\title{
KERATIN 10 IN INVESTIGATING THE HEALING POWER OF BONE MARROW DERIVED STEM CELLS COMPARE D TO MICROVESICLES IN TONGUE OF IRRADIATED ALBINO RATS
}

\author{
Dalia A. Elbaz*, Dina B. E. Farag ** and Tahany Haggag *
}

\begin{abstract}
Background: Multiple oral complications were reported in patients who receive radiotherapy for head and neck cancers.

Objectives: Investigating the healing power of bone marrow derived mesenchymal stem cells compared to microvesicles on dorsal lingual mucosa in irradiated albino rats.

Methods: 30 adult male albino rats were used. Rats were then divided randomly into three groups, 10 rats each. Group A: Irradiated rats received no treatment. Group B: Irradiated rats received a single dose of $1 \times 10^{6}$ bone marrow derived mesenchymal stem cells (BM-MSCs) injected intravenously, immediately after irradiation. Group $\boldsymbol{C}$ : Irradiated rats received a single dose of 30 $\mu \mathrm{g}$ microvesicles (derived from bone marrow stem cells) injected intravenously, immediately after irradiation. Each animal group was further divided into two subgroups (5 rats each) according to their date of scarification as follows: Subgroup I: The animals were sacrificed at day 3 following irradiation. Subgroup II: The animals were sacrificed at day 7 following irradiation. After scarification the tongue was dissected and examined histologically, histochemically and by real time-polymerase chain reaction (RT-PCR) for keratin 10 expression.
\end{abstract}

Results: Histologically, irradiated groups received no treatment (groups AI\&AII) showed marked epithelial and connective tissue degeneration. On the other hand both treated irradiated groups showed marked improved histological features (group B \& C) during both experimental periods ( 3 and 7 days). However the microvesicles treated group demonstrated normal histology especially at 7 days. Histochemical examination using masson's trichrome stain revealed an increased collagen density in groups (B \& C) as compared to group A during both experimental periods. This increase was statistically significant. RT-PCR results showed statistically significant increase in keratin 10 expression in groups (B \& C) as compared to group A during experimental periods I \& II.

Conclusions: Both BM-MSCs and microvesicles showed healing power in atrophied epithelium and connective tissue of dorsal lingual mucosa after radiotherapy, however treatment with microvesicles revealed more positive effect than BM-MSCs.

KEYWORDS: Radiotherapy, Bone marrow derived stem cells, Microvesicles, Keratin 10.

\footnotetext{
* Assistant Professor Oral Biology Department, Faculty of Dentistry, Cairo University.

** Lecturer, Oral Biology Department, Faculty of Dentistry, Cairo University.
} 


\section{INTRODUCTION}

Radiotherapy is a largely used line of treatment for malignancies of head and neck. Although radiotherapy when has been used alone or in combination with surgery or chemotherapy, has produced a significant improve in cure rates for many cases of head and neck malignancies, it is still associated with numerous and complex complications ${ }^{1}$.

Multiple oral complications were reported in patients who receive radiotherapy for head and neck cancers including oral pain, mucositis, xerostomia, dysgeusia, dental hypersensitivity, infection, and neurotoxicity ${ }^{2}$.

Stem cell therapy is emerging as a potentially revolutionary new way to treat disease and injury, with wide-ranging medical benefits ${ }^{3}$. Stem cells are cells that are characterized by unique properties of self-renewal and pleuripotency ${ }^{4}$. Mesenchymal stem cells (MSCs) are multipotent stem cells characterized by their ability to induce tissue repair, reduce inflammation and also they are of low immunogenicity ${ }^{5,6}$. Various studies have shown the successful role of stem cell therapies in the treatment of precancerous conditions, oral ulcers, wounds and mucositis ${ }^{7}$.

The recognition of microvesicles (MVs) as carriers of genetic information has opened a new era in the field of cell biology and pathophysiology ${ }^{8}$. MVs are plasma membrane-derived vesicles that are released into the microenvironment by various cell types, including stem cells and progenitors ${ }^{9}$. It has been proposed that microvesicles activate the intrinsic repair and regeneration processes by its mechanism of transferring genetic information ${ }^{10}$.

Bruno et al., ${ }^{11}$ demonstrated that microvesicles (MVs) derived from human bone marrow mesenchymal stem cells (BM-MSCs) stimulated proliferation of tubular epithelial cells in immunodeficient mice thus speeding up morphological and functional recovery from glycerol induced acute kidney injury.
Accordingly, the present work was established to evaluate the healing power of BM-MSCs compared to microvesicles derived from bone marrow stem cells on the dorsal lingual mucosa in irradiated rats using histological, histochemical as well as real time-polymerase chain reaction (RT-PCR) techniques.

\section{MATERIAL AND METHODS}

\section{Animals:}

Thirty adult male albino rats with average weight 150-200 gm were used in this study. The animals were obtained from the Animal house, Faculty of medicine, Cairo University, Egypt. All rats were kept in plastic cages maintained at a temperature of $22^{\circ} \mathrm{C} \pm 2{ }^{\circ} \mathrm{C}$ with a 12 -h light-dark cycle and allowed free access to food and water. All the animals care and experimental procedures were reviewed and approved by the institutional animal care and use committee (IACCUC), Cairo University.

\section{Experimental design:}

All rats were anaesthetized then received a single radiation dose of 10 Gray (Gy) to the head and neck region ${ }^{12}$. Rats were then divided randomly into three groups, 10 rats each.

Group A: Irradiated rats received no treatment.

Group B: Irradiated rats received a single dose of $1 \times 10^{6}$ bone marrow derived mesenchymal stem cells injected intravenously, immediately after irradiation $^{13}$.

Group C: Irradiated rats received a single dose of $30 \mu \mathrm{g}$ microvesicles (derived from bone marrow stem cells) injected intravenously, immediately after irradiation ${ }^{14}$.

Each animal group was further divided into two subgroups (5 rats each) according to their date of scarification as follows:

Subgroup I: The animals were sacrificed at day 3 following irradiation. 
Subgroup II: The animals were sacrificed at day 7 following irradiation.

\section{Experimental procedures}

\section{Rat Anesthesia:}

The animals were anaesthetized by intraperitoneal injection of ketamine chloride (ketalar ${ }^{\circledR} 40 \mathrm{mg} / \mathrm{kg}$ body weight) / sodium pentobarbital (Nembutal ${ }^{\circ}$, $40 \mathrm{mg} / \mathrm{kg}$ body weight).

\section{Radiation Exposure:}

Irradiation of the rats was performed at the National Cancer Institute Cairo, Egypt. A single dose of $10 \mathrm{~Gy} / \mathrm{min}$ was delivered directly to the head region of all the experimental animals using a Cobalt 60 source [energy 1.25 MV, THERATRON $780 \mathrm{E}]$.

\section{Preparation of BM-MSCs:}

Rat bone marrow (BM) was used for separation of mononuclear cells (MNCs). BM cells were flushed from tibia of white albino rat bones with Phosphate-Buffered Saline (PBS). $15 \mathrm{ml}$ of the flushed BM cells was carefully layered on $15 \mathrm{ml}$ Ficoll-Paque (Gibco-Invitrogen, Grand island, NY), then they were centrifuged for 35 minutes at $400 \mathrm{xg}$ rpm. The upper layer was aspirated leaving MNC layer undisturbed at the interphase. The interphase layer (MNC layer) was carefully aspirated and washed twice in PBS containing $2 \mathrm{~mm}$ Ethylene Diamine Tetra Acetic acid (EDTA) and centrifuged for 10 minutes at $200 \mathrm{xg} \mathrm{rpm}$ at $5^{\circ} \mathrm{C}$.

Isolated BM-MSCs were cultured and propagated on $25 \mathrm{ml}$ culture flasks in Roswell Park Memorial Institute (RPMI)-1640 medium supplemented with $10 \%$ Fetal Bovine Serum (FBS), $0.5 \%$ penicillin, streptomycin and incubated at $37^{\circ} \mathrm{C}$ and $5 \%$ carbon dioxide $\left(\mathrm{CO}_{2}\right)$ until reaching 80-90\% confluence within 7 days. Cultured MSCs were characterized by morphology and fluorescent analysis cell sorting (FACS) by assessment positivity of $\mathrm{CD}^{+} 0^{+}$and negativity of CD45 specific to MSCs.

\section{Isolation and identification of microvesicles (MV) derived from $\mathrm{BM}-\mathrm{MSCS}$}

MVs were isolated from supernatants of MSCs cultured overnight in RPMI deprived of Fetal Calf Serum (FCS). To obtain MVs, after centrifugation at $10,000 \mathrm{~g}$ for 20 minutes to remove debris, cellfree supernatants were centrif uged at 100,000 g (Beckman Coulter Optima L-90K ultracentrifuge) for one hour at $4^{\circ} \mathrm{C}$, washed in serum-free medium 199 containing N-2-Hydroxy Ethyl Piperazine-N'2-Ethane Sulfonic acid (HEPES) $25 \mathrm{mM}$ (Sigma) and submitted to a second ultracentrifugation in the same conditions. Briefly, MVs were characterized by transmission electron microscope (TEM) and by polymerase chain reaction (PCR) assessment of integrin gene expression.

MVs were fixed with $2.5 \%$ gluteraldehyde for 2 hours, after being washed; MVs were ultracentrifuged and suspended in $100 \mathrm{uL} \mathrm{HAS}$. A total of $20 \mathrm{uL}$ of MVs was loaded onto a formvar/carboncoated grid, negatively stained with $3 \%$ aqueous pjospho-tungestic acid for one minute and observed by TEM (HITACHI, H-7650, JAPAN). TEM performed on purified MVs showed their spheroid morphology and confirmed their size.

\section{Animal scarification and specimen preparation}

All animals were sacrificed by intraperitoneal injection of ketamine overdose and the tongue was dissected. A specimen of $5 \mathrm{~mm}$ in diameter was taken from the tongue to be subjected to RT-PCR examination. Specimens from the rest of the tongue were then prepared to produce paraffin-embedded specimens for light microscopy, according to the procedures described below:

\section{a- Light microscopic examination:}

Samples were fixed in $10 \%$ neutral formalin, washed, dehydrated in ethanol series, after which they were cleared in xylene and embedded in paraffin. 4-5 $\mu \mathrm{m}$ slices from dorsal surface of the tongue were prepared from paraffin embedded specimens and then stained as follows: 
- Heamatoxylin and Eosin for histopathological examination.

- Masson's trichrome for collagen fibers detection.

\section{b) Quantitative real time polymerase chain reac- tion (qRT-PCR):}

Tissues of all studied groups were lysed and total RNA was isolated with RNAeasy Mini Kit (Qiagen) and further analyzed for quantity and quality with Beckman dual spectrophotometer (USA). For quantitative expression of Keratin 10 target gene; the following procedure was assessed. $10 \mathrm{ng}$ of the total RNA from each sample were used for cDNA synthesis by reverse transcription using High capacity cDNA Reverse Transcriptase kit (Applied Biosystem, USA). The cDNA was subsequently amplified with the Syber Green I PCR Master Kit (Fermentas) in a 48-well plate using the Step One instrument (Applied Biosystem, USA) as follows: 10 minutes at $95{ }^{\circ} \mathrm{C}$ for enzyme activation followed by 40 cycles of 15 seconds at $95^{\circ} \mathrm{C}, 20$ seconds at 55 ${ }^{\circ} \mathrm{C}$ and 30 second at $72{ }^{\circ} \mathrm{C}$ for the amplification step. Changes in the expression of each target gene were normalized relative to the mean critical threshold (CT) values of GAPDH as housekeeping gene by the $\Delta \Delta \mathrm{Ct}$ method. We used $1 \mu \mathrm{M}$ of both primers specific for each target gene. Primers sequence and annealing temperature specific for each gene demonstrated in table (1).

\section{Image Analysis:}

The color area percentage of collagen fibers (blue colored) in Masson's trichrome stained sections was measured by an image analysis system (Leica DM LB2 with QWIN Plus image analyzer computer system, Germany). Image analysis was done in ten small measuring frames; in each specimen using an objective lens of magnification 400x.

\section{Statistical analysis:}

Data obtained from both image analysis and RTPCR were statistically described in terms of mean \pm standard deviation $( \pm$ SD). Pair wise comparison between the studied groups was done using students t-test. $\quad p$ values less than 0.05 was considered statistically significant. All statistical calculations were done using computer program SPSS (Statistical Package for the Social Science; SPSS Inc., Chicago, IL, USA) release 15 for Microsoft Windows (2006).

\section{RESULTS}

\section{Histological Results}

\section{(Group AI) Untreated irradiated group after 3 days:}

The dorsal surface of the tongue showed disturbed pattern of the filiform papillae and keratin tips were lost over some papillae. Degeneration with obvious thinning and marked vacuolization of keratinized stratified squamous epithelium were observed. Irregular epithelial retepegs were noticed. The underlying connective tissue was severely degenerated with massive vacuolization. (Fig.1a)

TABLE (1): Primers sequence and annealing temperature specific for each gene

\begin{tabular}{|l|l|l|}
\hline Target gene & Primer sequence: 5'-3' & Gene bank accession number \\
\hline Keratin 10 & $\begin{array}{l}\text { F: AGCATGGCAACTCACATCAG } \\
\text { R: TGTCGATCTGAAGCAGGATG }\end{array}$ & BC_034697.1 \\
\hline GAPDH & $\begin{array}{l}\text { F: GAGTCAACGGATTTGGTCGT } \\
\text { R: TTGATTTTGGAGGGATCTCG }\end{array}$ & NM_002046.4 \\
\hline
\end{tabular}


(Group BI) Irradiated group treated with BMMSCs after 3 days:

The dorsal surface of the tongue showed filiform papilla covered by keratinized stratified squamous epithelium with relatively definite cell layers as compared to untreated irradiated group except for some areas showed hyalinization in basal and parabasal layer. Some vacuolated cells were also noticed especially between the basal cells. Disturbance in the arrangement of basal cell layer was also observed. The underlying connective tissue showed areas of dissociation and vacuolization. Dilated blood vessels were noticed. (Fig.1b)

(Group CI) Irradiated group treated with MVs after 3 days:

As compared to groups $\mathrm{AI}$ and $\mathrm{BI}$ the dorsal surface of the tongue exhibited nearly normal pattern of filiform papillae. The basal cell showed normal architecture except for some areas of hyalinization. Few areas of underlying connective tissue dissociation as well as vacuolization were still evident. (Fig.1c)

\section{(Group AII) Untreated irradiated group after 7 days:}

The dorsal surface of the tongue exhibited ill-defined filiform papilla in some areas.
The covering epithelium showed partial regeneration with indistinct epithelial layers. Indefinite epithelial cells boundaries and vacuolated cells could also be observed. The underlying connective tissue seemed hyalinized in some areas and dissociated in other areas. (Fig.2a)

\section{(Group BII) Irradiated group treated with BM- MSCs after 7 days:}

Keratinized stratified squamous epithelium demonstrated well defined epithelial cell arrangement with preserved keratin tips over the filliform papillae. Few vacuolated cells were observed. The underlying connective tissue showed relatively well defined architecture. Dilated blood vessels were noted. (Fig.2b)

\section{(Group CII) Irradiated group treated with MVs af- ter 7 days:}

The dorsal surface of the tongue revealed regularly oriented prominent filiform papilla with normal covering keratinized stratified squamous epithelium formed of well-arranged and definite cell layers. Scattered vacuolated cells were noticed. Well-formed organized underlying connective tissue was demonstrated. (Fig.2c)

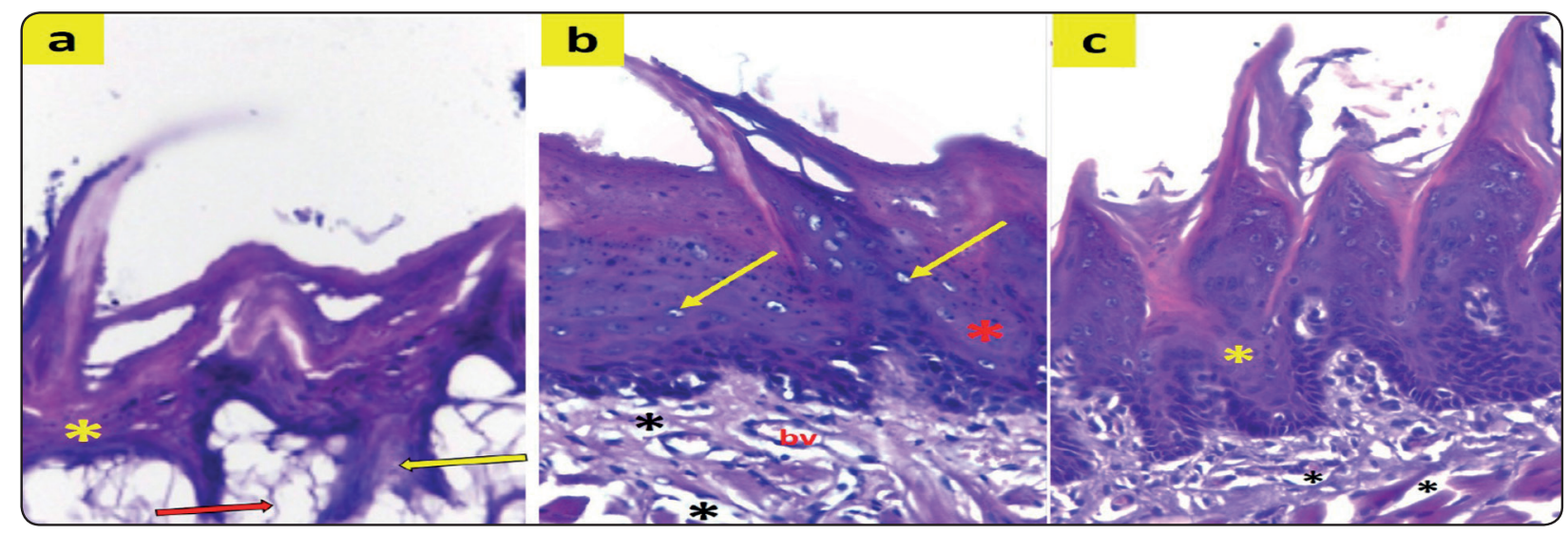

Fig. (1) Photomicrograph of the dorsal surface of the tongue showing (a) thinning of stratified squamous epithelium (asterisk), irregular epithelial retepegs (yellow arrow), degenerated underlying connective tissue (red arrow).(b) epithelial hyalinization (red asterisk), vacuolated epithelial cells (yellow arrows), dilated blood vessel (bv), dissociated and vacuolated areas of connective tissue (black asterisks). (c) epithelial hyalinization (yellow asterisk), connective tissue vacuolization (black asterisks). (H\&E, Orig. Mag. $\times 400)$ 


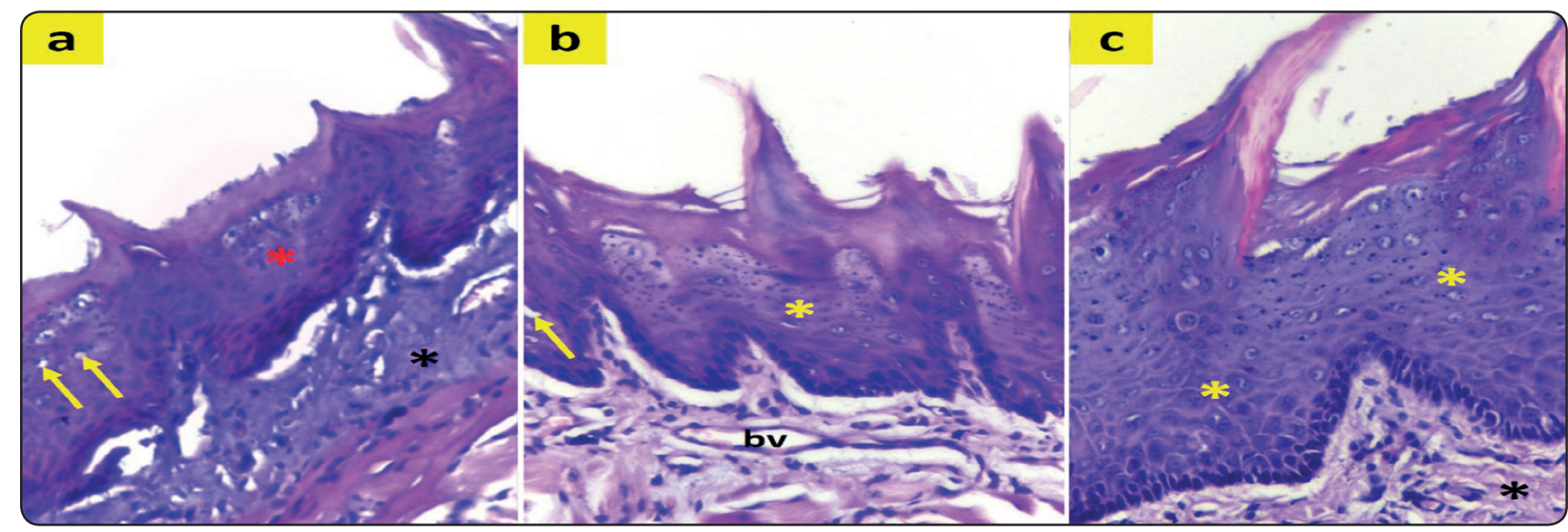

Fig. (2) Photomicrograph of the dorsal surface of the tongue showing (a) indefinite epithelial cell boundaries (red asterisk), cellular vacuolization (yellow arrows), hyalinized connective tissue (black asterisk). (b) well defined epithelial arrangement (yellow asterisk), vacuolization (yellow arrow), dilated blood vessel (bv). (c) well-arranged and defined epithelial cells (yellow asterisks), well-formed organized connective tissue (black asterisk). (H\&E, Orig. Mag. ×400)

\section{Histochemical Results}

\section{Group AI}

Three days after irradiation, Masson's trichromestained sections of irradiated untreated group showed fine loose randomly arranged collagen fibers (Fig.3a). The lowest mean value of collagen colored area percentage was revealed in this group $(2.523 \pm 0.259)$. (Column chart 1$)$

\section{Group BI}

On the other hand, group (BI) demonstrated increase in the density of collagen fibers (Fig.3b) where the mean value was (7.326 \pm 0.719$)$ (Column chart 1). Statistical analysis revealed that this increase was statistical significant as compared to group $\mathrm{AI}(\mathrm{P}=<0.0001)$.

\section{Group CI}

The density of collagen fibers was increased in this group (Fig.3c) as the mean value for color area percentage of collagen was $(9.269 \pm 1.246)$ (Column chart 1). This increase was statistically significant when compared with both group AI $(\mathrm{P}=<0.0001)$ and group $\mathrm{BI}(\mathrm{P}=0.0005)$.

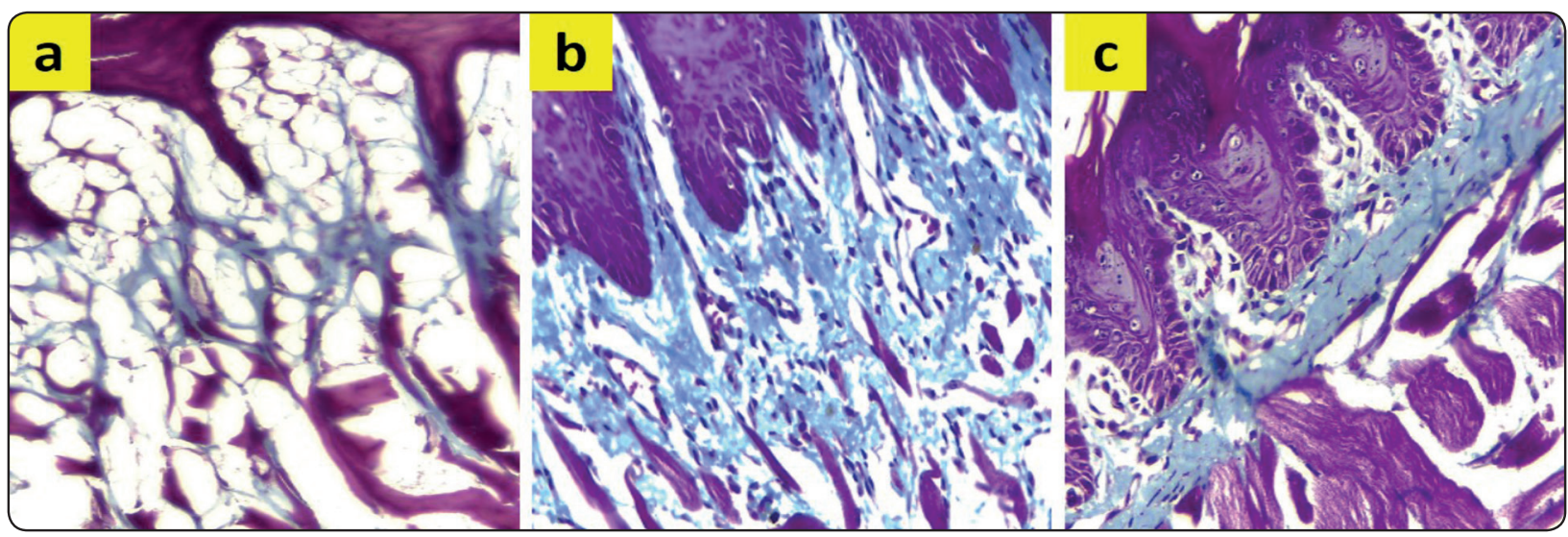

Fig. (3) Photomicrograph of masson's trichrome histochemical activity showing: (a) fine loosely arranged blue stained collagen fibers. (b) increase density of blue stained collagen fibers. (c) relatively organized bundles of blue stained collagen fibers. (Orig. Mag. X400) 


\section{Group AII}

Following the irradiation by seven days, Masson's trichrome-stained sections of irradiated untreated group showed thin scattered bundles of collagen fibers (Fig. 4a). The mean value for color area percent of collagen was $4.727 \pm 0.874$. (Column chart 1)

\section{Group BII}

This group revealed increase in the density of coarse collagen fibers (Fig. 4b). The mean value for color area percentage of collagen was $9.98 \pm 0.863$ (Column chart 1). As compared to group AII this increase was statistically significant $(\mathrm{P}=<0.0001)$.

\section{Group CII}

Collagen fibers in this group were arranged regularly in dense bundles (Fig. 4c). There was marked increase in the density of collagen fibers as this group demonstrated the highest mean value for collagen color area percentage $14.87 \pm 0.78$ (Column chart 1). This increase was statistically significant when compared with both group AII (P $<0.0001)$ and group BII $(\mathrm{P}<0.0001)$.

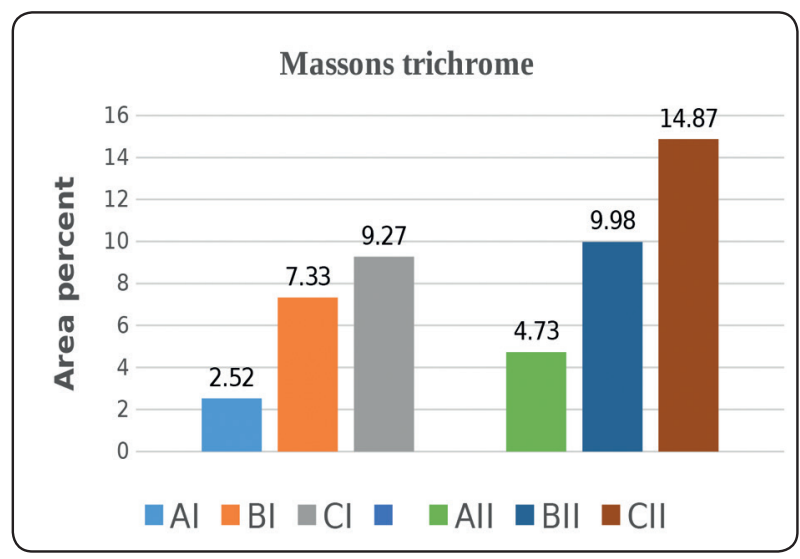

Column chart (1): Represent mean values of color area percent of blue stained collagen in all studied groups.

\section{Quantitative RT- PCR results for keratin $10 \mathrm{ex}$ -} pression

\section{Group AI}

After 3 days, the untreated irradiated group showed the lowest mean value for keratin 10 expression which was $0.583 \pm 0.12$. (Column chart 2)

\section{Group BI}

Stem cells treated irradiated group showed an increase in mean value of keratin 10 expression $1.963 \pm 0.33$ (Column chart 2). This increase was statistically significant as compared to group AI $(\mathrm{P}<0.0001)$.

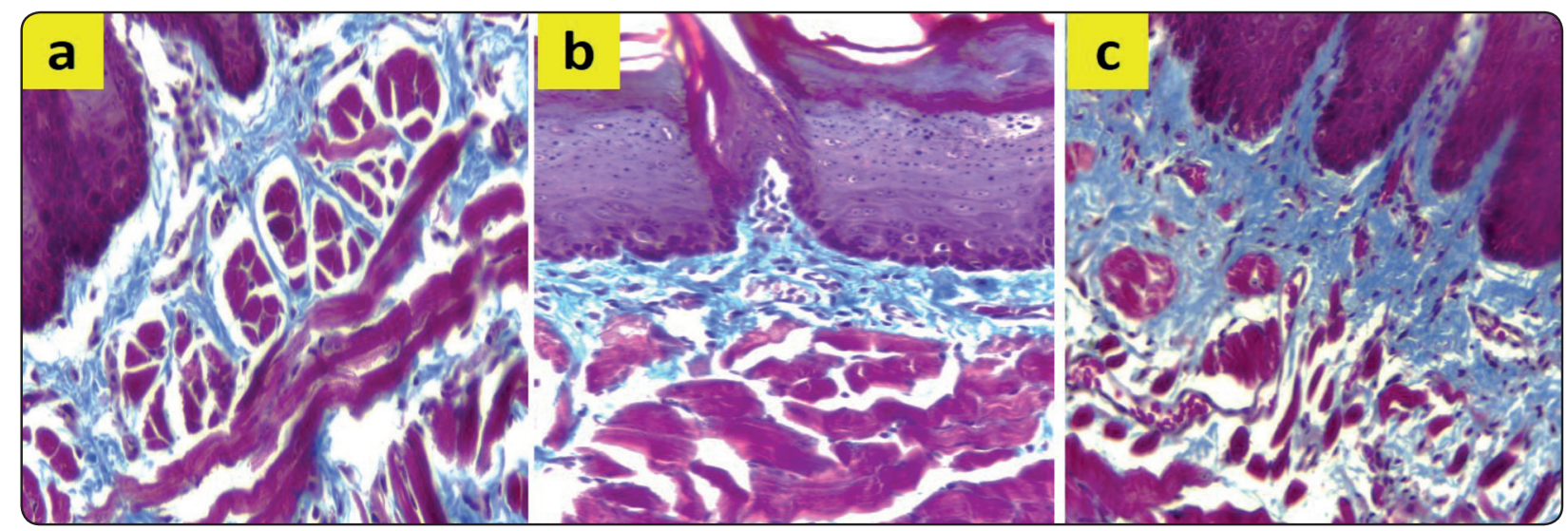

Fig. (4) Photomicrograph of masson's trichrome histochemical activity showing: (a) thin scattered bundles of blue stained collagen fibers. (b) well-formed coarse blue stained collagen fibers. (c) compact and dense bundles of blue stained collagen fibers. (Orig. Mag. X400) 


\section{Group CI}

In microvesicles treated irradiated group the mean value of keratin 10 expression was $2.755 \pm 0.41$ (Column chart 2), which was significantly increased compared with both group AI $(\mathrm{P}<0.0001)$ and group $\mathrm{BI}(\mathrm{P}<0.0002)$.

\section{Group AII}

Following 7 days from irradiation, the mean value recorded for keratin 10 expression in untreated group was $(0.644 \pm 0.11)$. (Column chart 2)

\section{Group BII}

Irradiated group treated with stem cells showed an increase in mean value of keratin 10 expression 2.316 \pm 0.51 (Column chart 2). This increase was statistically significant as compared to group AII $(\mathrm{P}<0.0001)$.

\section{Group CII}

The greatest mean value of keratin 10 expression was observed in the irradiated group treated with microvesicles (2.974 \pm 0.62$)$ (Column chart 2). This was significantly increased compared with both group AII $(\mathrm{P}<0.0001)$ and group BII $(\mathrm{P}<0.018)$.

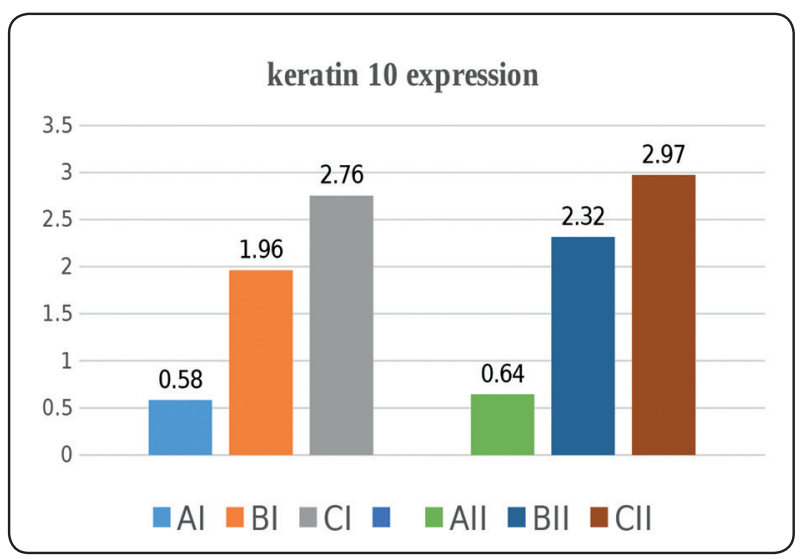

Column chart (2): Represent mean values for keratin 10 expression in all the studied groups.

\section{DISCUSSION}

Radiotherapy has been widely used in treating malignant lesions on the head and neck, with improvement in patient survival rates. Since radiotherapy-induced oral complications and a decrease in quality of life the field of regenerative medicine considers the promise of treating radiation related adverse effects. Mesenchymal stem cells as well as microvesicles with their versatile biological potential are of great interest in regenerative medicine ${ }^{15,16}$.

Therefore, the current study was carried out to evaluate histologically, histochemically and by RT-PCR the effect of bone marrow derived mesenchymal stem cells compared to microvesicles on tongue of irradiated rats as a trial for preventing, controlling or even minimizing the adverse side effects induced by radiotherapy in the dorsal surface of the tongue.

In the present study, the histological results of the group AI (3 days following irradiation) showed disturbed pattern of filiform tongue papillae with loss of the keratin tips. Thinning of the epithelium thickness with areas of vacuolization. The underlying connective tissue showed areas of vacuolization and dissociation. The reduction in epithelial thickness of the tongue of irradiated rat was in agreement with the results of Zhao et al., ${ }^{17}$ who reported reduced mucosal thickness in ventral surface of the tongue of mice at 4 days following irradiation. Redding ${ }^{18}$ explained that, the acute mucosal response to radiotherapy is due to basal cell death of the mucosal epithelium, reducing its regenerative capacity and leading to thinning and ulcerations of epithelium. In addition, other researchers stated that radiation activates various cellular signaling pathways ${ }^{19}$ that lead to expression and activation of proinflammatory and profibrotic cytokines ${ }^{20}$.

Signs of partial regeneration were demonstrated in group AII (7 days following irradiation). 
However, ill-defined boundaries and vacuoles were noted in the epithelial cells. These results were in agreement with those of Barcellos-Hoff ${ }^{21}$, who demonstrated that following the irradiation, the tissue activates a rapid molecular response as production of cytokines, which leads to an adaptive response in the surrounding tissue and cellular infiltration. Damage to the vasculature and release of vasoactive cytokines enable fibrin to leak into the tissues, which promotes collagen deposition.

Regarding MSCs groups BI\&BII the histological results revealed, restoration of filiform papillae pattern with relative improvement of epithelium and connective tissue architecture. These results were in accordance with Semont et al. ${ }^{22}$ who demonstrated that BM-MSC transplantation improved the recovery of the small intestine (after radiation), both structurally and functionally and extended the life of mice. This was attributed to the enhancement of regeneration ability of intestinal epithelium and inhibition of radiation-induced apoptosis.

Granero-Moltó et al., ${ }^{23}$ demonstrated that at the injury site, MSCs could help in repair in two ways; first by differentiating into tissue cells in order to restore lost morphology and function and second by secreting of bioactive factors that have anti-apoptotic and immune-regulatory properties. Moreover, it has been proposed that, beside MSCs ability to differentiate into many cell lines, the secretion of a wide range of biological molecules by MSCs, such as cytokines and chemokines, establishes their biologically effective role under condition of injury ${ }^{24-28}$.

Additionally, Baraniak \& McDevitt ${ }^{29}$ reported that MSCs secrete many growth factors including vascular endothelial growth factor (VEGF), hepatocyte growth factor (HGF), insulin-like growth factors (IGF)-1, stromal cell-derived factor (SDF), basic fibroblast growth factor (bFGF), transforming growth factor (TGF)- $\beta$, and platelet derived growth factor (PDGF).
There are several researches on paracrine action of stem cells and their role in tissue regeneration ${ }^{30,31}$. Paracrine effect of stem cells is exerted through microparticles. These are membrane-coated particles named microvesicles contained protein and RNA, released during the activation of cells or $\operatorname{apoptosis}^{32,33}$.

Concerning MVs groups, the histological results revealed basal cells with normal architecture except for some areas of hyalinization in CI group and nearly normal histological structures of stratified squamous epithelium of dorsal surface of the tongue with definite cellular outlines in group CII. Well organized connective tissue was also evident. These results were in agreement with Herrera et al. ${ }^{14}$ who demonstrated that human liver stem cells derived MVs accelerated regeneration of the liver in rats with $70 \%$ hepatectomy as the MVs enhanced hepatocyte proliferation and significantly reduced apoptosis. Also, Gatti et al., ${ }^{34}$ found that administration of mesenchymal stem cells-derived MVs limited acute injury in a model of renal ischemic injury by inhibiting apoptosis and stimulating proliferation, and also prevented the development of chronic renal disease.

The effect of microvesicle treatment observed in the herein results could be explained by Ratajczak et al., ${ }^{35}$ who demonstrated that, the biological effect of MVs was strongly dependent on mRNA present in these MVs, as pretreatment of MVs with RNAse abolished this protective effect. In addition to mRNA, other components of MVs, such as sphingosine-1-phosphate S1P (one of the lipids'component of cell membrane), could also play an essential role as it inhibits cell apoptosis and stimulates angiogenesis.

It has been reported that MVs derived from BM-MSCs shuttle sufficient quantities of mRNA that support synthesis of cDNA. Also MVs contain micro RNA (miRNA) that is found only in the MVs and absent in the cell itself, which suggests that 
some miRNA is uniquely packed in MVs. Some of these miRNA sequences code for angiogenesis and haematopoeisis $^{36-38}$.

Moreover, Bruno et al., ${ }^{39}$ investigated the mechanism of anti-apoptotic effect of MVs and they reported that MVs up-regulate some anti-apoptotic genes such as BclxL, Bcl2 and BIRC8 and downregulate other genes that have a vital role in cell apoptosis such as Casp1, Casp8 and LTA.

Collagen measurement and arrangement is very essential in wound healing as the collagen restores the integrity, anatomic structure as well as function of the tissue ${ }^{40}$. Histochemical analysis in the current study was performed using masson's trichrome stain (MT). By using this special staining, collagen fibers which were not differentiable using haematoxylin and eosin (H\&E) staining could be clearly seen represented by its blue colour. This could be help in evaluating collagen deposition, density, reorganization and differentiate between fine and coarse collagen fibers ${ }^{40}$.

The histomorphometric results of the present study revealed a significant increase in collagen area \% in MVs treated groups CI\&II (the greatest mean values $(9.269 \pm 1.246 \& 14.87 \pm 0.78$ respectively) and in BM-MSCs treated groups BI\&II (7.326 $\pm 0.719 \& 9.98 \pm 0.863$ respectively) as compared to irradiated untreated groups AI \& AII (the lowest mean values $2.523 \pm 0.259 \&$ $4.727 \pm 0.874$ respectively) $(\mathrm{P}=<0.0001)$. The latter findings support our histopathological results which revealed marked positive effect of MVs on regeneration of the mucosa of the dorsal surface of the tongue.

Keratins are cytoskeletal proteins that are expressed in epithelial cells ${ }^{41}$. These proteins are classified as type I or type II keratins based on biochemical characteristics such as molecular weight $^{42}$. Keratin 10 (K10) is a type I keratin that is expressed in post-mitotic suprabasal keratinocytes of the skin and oral mucosa. It has been suggested that K10 expression inhibits cell cycle progression and thus directly contributes to terminal keratinocyte differentiation ${ }^{43,44}$. Loss of K10 in the suprabasal epidermis leads to increased proliferation of basal cells and accelerated migration of keratinocytes from the basal cell layer to the skin surface ${ }^{45}$.

Interestingly, RT-PCR results of keratin 10 gene expression in the current research corroborated with the histopathological results, where the lowest mean values were recorded in untreated irradiated groups AI\&II $(0.583 \pm 0.12$. \& $0.644 \pm 0.11$ respectively $)$. This observed marked decrease in keratin 10 expression in the present study could be explained by Donetti et al., ${ }^{44}$ who reported that reduction of keratin 10 expression indicates overall alteration in the process of keratinocyte terminal differentiation.

On the other hand, the greatest mean values of keratin 10 were recorded in MVs treated groups CI\&II (2.755 $\pm 0.41 \& \quad 2.974 \pm 0.62$ respectively), followed by BM-MSCs treated groups BI\&II $(1.963 \pm 0.33 \& \quad 2.316 \pm 0.51$ respectively). The difference between both treated groups was statistically significant at each scarification date. This later finding indicates the superior effect of MVs over BM-MSCs on terminal differentiation of keratinocyte.

\section{CONCLUSION}

BM-MSCs as well as MVs were able to enhance the healing power in atrophied mucosa of dorsal surface of tongue of irradiated rats. However, MVs can elicit better outcome. Furthermore, additional experiments are required to investigate long term safety of microvesicles adminstration.

\section{REFERENCES}

1- Otmani N. Oral and maxillofacial side effects of radiation therapy on children. J Can Dent Assoc (2007); 73:257-261.

2- Peterson DE. Oral problems in supportive care: no longer an orphan topic? Support Care Cancer (2000); 8:347-348.

3- Slack JM. Stem cells in epithelial tissues. Science (2000); 
287: $1431-1433$

4- Kagami H, Wang S, Hai B. Restoring the function of salivary glands. Oral Diseases (2008); 14:15-24.

5- Khalili S, Liu Y, Kornete M, Roescher N, Kodama S, Peterson A, Tran SD. Mesenchymal Stromal Cells Improve Salivary Function and Reduce Lymphocytic Infiltrates in Mice with Sjögren's-Like Disease. PLoS One (2012); 7:e38615.

6- Xu J, Wang D, Liu D, Fan Z, Zhang H, Liu O., Ding G, Gao R, Zhang C, Ding Y, Bromberg JS, Chen W, Sun L, Wang S. Allogeneic mesenchymal stem cell treatment alleviates experimental and clinical Sjögren syndrome. Blood (2012); 120:3142-3151.

7- Devi P, Thimmarasa VB, Jayadev S, Mehrotra V, Arora P. Stem cells: Treading the unexplored path. J Oral Sign (2010); 2:41-45.

8- Pap E, Pallinger E, Pasztoi M, Falus A. Highlights of a new type of intercellular communication: microvesicle based information transfer. Inflam Res (2009); 58:1-8.

9- Raposo G, Stoorvogel W. Extracellular vesicles: Exosomes, microvesicles, and friends. J Cell Biol (2013); 200: 373-383.

10- Anthony DF, and Shiels PG. Exploiting paracrine mechanisms of tissue regeneration to repair damaged organs. Transplant Res (2013); 2: 10.

11- Bruno S, Grange C, Deregibus MC, Calogero RA, Saviozzi S, Collino F, Morando L, Busca A, Falda M, Bussolati B, Tetta C, Camussi G. Mesenchymal Stem Cell-Derived Microvesicles Protect Against Acute Tubular Injury. J Am Soc Nephrol (2009); 20:1053-1067.

12- Peng Z, Xu ZW, Wen WS, Wang RS. Tea polyphenols protect against irradiation-induced injury in submandibular glands' cells: A preliminary study. Archives of Oral Biology (2011); 56:738-743.

13- Schwarz S, Huss R, Schulz-Siegmund M, Vogel B, Brandau S, Lang S, Rotter N. Bone marrow-derived mesenchymal stem cells migrate to healthy and damaged salivary glands following stem cell infusion. International Journal of Oral Science (2014); 6:154-61.

14- Herrera MB, Fonsato V, Gatti S, Deregibus MC, Sordi A, Cantarella D, Camussi G. Human liver stem cellderived microvesicles accelerate hepatic regeneration in hepatectomized rats. Journal of Cellular and Molecular Medicine (2010); 14:1605-1618.
15- Spetch L. Oral complications in the head and neck irradiated patient. Introduction and scope of the problem. Supp Care Dent (2002); 10: 36- 39.

16- Biancone L, Bruno S, Deregibus MC, Tetta C, Camussi G. Therapeutic potential of mesenchymal stem cell-derived microvesicles. Nephrol Dial Transplant (2012); 27: 3037 3042 .

17- Zhao J, Kim KA, De Vera J, Palencia S, Wagle M, Abo A. R-Spondin1 protects mice from chemotherapy or radiation-induced oral mucositis through the canonical Wnt/beta-catenin pathway. Proc Natl Acad Sci U S A (2009); 106: 2331-2336.

18- Redding SW. Cancer therapy-related oral mucositis. J Dent Educ (2005); 69: 919-929.

19- Dent P, Yacoub A, Contessa J, Caron R, Amorino G, Valerie K, Hagan MP, Grant S, Schmidt-Ullrich R. Stress and radiation-induced activation of multiple intracellular signaling pathways. Radiat Res (2003); 159: 283-300.

20- Chen Y, Williams J, Ding I, Hernady E, Liu W, Smudzin T, Finkelstein JN, Rubin P, Okunieff P. Radiation pneumonitis and early circulatory cytokine markers. Semin Radiat Oncol (2002); 12: 26-33.

21- Barcellos-Hoff MH. How do tissues respond to damage at the cellular level? The role of cytokines in irradiated tissues. Radiat Res (1998); 150: S109-120.

22- Sémont A, Mouiseddine M, Francois A, Demarquay C, Mathieu N, Chapel A, Saché A, Thierry D, Laloi P, Gourmelon P. Mesenchymal stem cells improve small intestinal integrity through regulation of endogenous epithelial cell homeostasis. Cell Death Differ (2010); 17:952-961.

23- Granero-Moltó F, Weis JA, Miga MI, Landis B, Myers TJ, O'Rear L, Longobardi L, Jansen ED, Mortlock DP, Spagnoli A. Regenerative effects of transplanted mesenchymal stem cells in fracture healing. Stem Cells (2009); 27: 1887-1898.

24- Haynesworth SE, Baber MA, Caplan AI. Cytokine expression by human marrow-derived mesenchymal progenitor cells in vitro: effects of dexamethasone and IL-1 $\alpha$ J Cell Physiol (1998); 166:585-592.

25- Baddoo M, Hill K, Wilkinson R, Gaupp D, Hughes C, Kopen GC,Phinney DG. Characterization of mesenchymal stem cells isolated from murine bone marrow by negative selection. J Cell Biochem (2003); 89:1235-1249. 
26- Tögel F, Weiss K, Yang Y, Hu Z, Zhang P, Westenfelder C. Vasculotropic, paracrine actions of infused mesenchymal stem cells are important to the recovery from acute kidney injury. Am J Physiol Renal Physiol (2007); 292:16261635.

27- Block GJ, Ohkouchi S, Fung F, Frenkel J, Gregory C, Pochampally R. Multipotent stromal cells are activated to reduce apoptosis in part by upregulation and secretion of stanniocalcin-1. Stem Cells (2009); 27:670-681.

28- Martinet L, Fleury-Cappellesso S, Gadelorge M, Dietrich G, Bourin P, Fournié JJ, Poupot R. A regulatory crosstalk between Vgamma 9 Vdelta2 $\mathrm{T}$ lymphocytes and mesenchymal stem cells. Eur J Immunol (2009); 39:752762

29- Baraniak PR, McDevitt TC. Stem cell paracrine actions and tissue regeneration. Regen Med (2010); 5:121-43.

30- Burdon TJ, Paul A, Noiseux N, Prakash S, Shum-Tim D. Bone marrow stem cell derived paracrine factors for regenerative medicine: current perspectives and therapeutic potential. Bone marrow research. (2011); 2011:207326.

31- Ratajczak MZ, Kucia M, Jadczyk T, Greco NJ, Wojakowski W, Tendera M, Ratajczak J. Pivotal role of paracrine effects in stem cell therapies in regenerative medicine: can we translate stem cell-secreted paracrine factors and microvesicles into better therapeutic strategies?. Leukemia (2012); 26:1166-1173.

32-Distler JH, Pisetsky DS, Huber LC, Kalden JR, Gay S, Distler O. Microparticles as regulators of inflammation: novel players of cellular crosstalk in the rheumatic diseases. Arthritis and rheumatism (2005); 52:3337-3348.

33- Distler JH, Huber LC, Gay S, Distler O, Pisetsky DS. Microparticles as mediators of cellular cross-talk in inflammatory disease. Autoimmunity (2006); 39:683-90.

34- Gatti S, Bruno S, Deregibus M C, Sordi A, Cantaluppi V, Tetta C, Camussi G. Microvesicles derived from human adult mesenchymal stem cells protect against ischaemiareperfusion-induced acute and chronic kidney injury. Nephrology Dialysis Transplantation (2011); 26: 1474 1483 .

35- Ratajczak MZ, Lee H, Wysoczynski M, Wan W, Marlicz W, Laughlin MJ, Kucia M, Janowska-Wieczorek A, Ratajczak J. Novel insight into stem cell mobilization-plasma sphingosine-1-phosphate is a major chemoattractant that directs the egress of hematopoietic stem progenitor cells from the bone marrow and its level in peripheral blood increases during mobilization due to activation of complement cascade/membrane attack complex. Leukemia (2010); 24: 976-985.

36- Alvarez-Garci I, Miska EA, Hedgecock EM. MicroRNA functions in animal development and human disease. Development (Cambridge, England) (2005); 132:46534662 .

37- Wienholds E, Plasterk RHA. MicroRNA function in animal development. FEBS Letters (2005); 579:5911-5922.

38- Valadi H, Ekström K, Bossios A, Sjöstrand M, Lee JJ, Lötvall JO. Exosome-mediated transfer of mRNAs and microRNAs is a novel mechanism of genetic exchange between cells. Nature Cell Biology (2007); 9:654-659.

39- Bruno S, Grange C, Collino F, Deregibus MC, Cantaluppi V, Biancone L, Tetta C, Camussi G. Microvesicles derived from mesenchymal stem cells enhance survival in a lethal model of acute kidney injury. PLoS One (2012); 7:1-11.

40- Suvik A, Effendy AWM. The use of modified masson's trichrome staining in collagen evaluation in wound healing study. Malaysian Journal Veterinary Research (2012); 3:39-47

41- Rogers MA, Edler L, Winter H, Langbein L, Beckmann I, Schweizer J. Characterization of new members of the human type II keratin gene family and a general evaluation of the keratin gene domain on chromosome 12q13.13. J. Invest Dermatol (2005); 124:536-544.

42- Coulombe PA, Wong P. Cytoplasmic intermediate filaments revealed as dynamic and multipurpose scaffolds. Nat. Cell Biol (2004); 6: 699-706.

43- Koch PJ, Roop DR. The role of keratins in epidermal development and homeostasis--going beyond the obvious. J Invest Dermatol (2004);123:x-xi.

44- Donetti E, Gualerzi A, Bedoni M, Volpari T, Sciarabba M, Tartaglia G, Sforza C. Desmoglein 3 and keratin 10 expressions are reduced by chronic exposure to cigarette smoke in human keratinised oral mucosa explants. Arch Oral Biol (2010); 55:815-823.

45- Reichelt J, Furstenberger G, Magin TM. Loss of keratin 10 leads to mitogen-activated protein kinase (MAPK) activation, increased keratinocyte turnover, and decreased tumor formation in mice. J. Invest Dermatol (2004); 123:973-981. 